\title{
Analyzing moisture-heat coupling in a wheat-soil system using data-driven vector autoregression model
}

\author{
Xiaohang Feng ${ }^{\text {Corresp., } 1,2}$, Xia Zhang ${ }^{1}$, Zhenqi Feng $^{1}$, Yichang Wei ${ }^{1}$ \\ ${ }^{1}$ North China University of Water Resources Electric Power, Zhengzhou, Henan, China \\ 2 Peking University, Beijing, China \\ Corresponding Author: Xiaohang Feng \\ Email address: 1600018809@pku.edu.cn
}

Soil temperature and moisture have a close relationship, the accurate controlling of which is important for crop growth. Mechanistic models built by previous studies need exhaustive parameters and seldom consider time stochasticity and lagging effect. To circumvent these problems, this study designed a data-driven stochastic model analyzing soil moisture-heat coupling. Firstly, three vector autoregression models are built using hourly data on soil moisture and temperature at the depth of $10 \mathrm{~cm}, 30 \mathrm{~cm}$, and $90 \mathrm{~cm}$. Secondly, from impulse response functions, the time lag and intensity of two variables' response to one unit of positive shock can be obtained, which describe the time length and strength at which temperature and moisture affect each other, indicating the degree of coupling. Thirdly, Granger causality tests unfold whether one variable's past value helps predict the other's future value. Analyzing data obtained from Shangqiu Experiment Station in Central China, we obtained three conclusions. Firstly, moisture's response time lag is $25 \mathrm{~h}, 50 \mathrm{~h}$, and $120 \mathrm{~h}$, while temperature's response time lag is $50 \mathrm{~h}, 120 \mathrm{~h}$, and $120 \mathrm{~h}$ at $10 \mathrm{~cm}, 30$ $\mathrm{cm}$, and $90 \mathrm{~cm}$. Secondly, temperature's response intensity is $0.2004^{\circ} \mathrm{C}, 0.0163^{\circ} \mathrm{C}$ and $0.0035^{\circ} \mathrm{C}$ for $1 \%$ variation in moisture, and moisture's response intensity is $0.0638 \%$, $0.0163 \%$ and $0.0050 \%$ for $1{ }^{\circ} \mathrm{C}$ variation in temperature at $10 \mathrm{~cm}, 30 \mathrm{~cm}$ and $90 \mathrm{~cm}$. Thirdly, the past value of soil moisture helps predict soil temperature at $10 \mathrm{~cm}, 30 \mathrm{~cm}$, and $90 \mathrm{~cm}$. Besides, the past value of soil temperature helps predict soil moisture at $10 \mathrm{~cm}$ and $30 \mathrm{~cm}$, but not at $90 \mathrm{~cm}$. We verified this model by using data from a different year and linking it to Soil Plant Atmospheric Continuum model. 


\section{Manuscript Title}

2 Xiaohang Feng ${ }^{1,2^{*}}$ Xia Zhang ${ }^{1}$ Zhenqi Feng ${ }^{1}$ Yichang Wei $^{1}$

$3{ }^{1}$ North China University of Water Resources Electric Power, Zhengzhou, Henan, China; ${ }^{2}$ Peking University, Beijing,

4 China

5 Corresponding Author:

6 Xiaohang Feng ${ }^{1,2^{*}}$

7 Email address: 1600018809@pku.edu.cn; Tel.: +86-18811776315 


\section{Analyzing Moisture-heat Coupling in a Wheat-soil System Using Data- 9 driven Vector Autoregression Model}

10 Xiaohang Feng ${ }^{1,2^{*}}$ Xia Zhang ${ }^{1}$ Zhenqi Feng ${ }^{1}$ Yichang Wei ${ }^{1}$

$11{ }^{1}$ North China University of Water Resources Electric Power, Zhengzhou, Henan, China; ${ }^{2}$ Peking University, Beijing,

12 China

$13{ }^{*}$ Corresponding Author, Email: 1600018809@pku.edu.cn; Tel.: +86-18811776315

Abstract: Soil temperature and moisture have a close relationship, the accurate controlling of which is important for crop growth. Mechanistic models built by previous studies need exhaustive parameters and seldom consider time stochasticity and lagging effect. To circumvent these problems, this study designed a data-driven stochastic model analyzing soil moisture-heat coupling. Firstly, three vector autoregression models are built using hourly data on soil moisture and temperature at the depth of $10 \mathrm{~cm}, 30 \mathrm{~cm}$, and $90 \mathrm{~cm}$. Secondly, from impulse response functions, the time lag and intensity of two variables' response to one unit of positive shock can be obtained, which describe the time length and strength at which temperature and moisture affect each other, indicating the degree of coupling. Thirdly, Granger causality tests unfold whether one variable's past value helps predict the other's future value. Analyzing data obtained from Shangqiu Experiment Station in Central China, we obtained three conclusions. Firstly, moisture's response time lag is $25 \mathrm{~h}, 50 \mathrm{~h}$, and $120 \mathrm{~h}$, while temperature's response time lag is $50 \mathrm{~h}, 120 \mathrm{~h}$, and 120 $\mathrm{h}$ at $10 \mathrm{~cm}, 30 \mathrm{~cm}$, and $90 \mathrm{~cm}$. Secondly, temperature's response intensity is $0.2004^{\circ} \mathrm{C}, 0.0163^{\circ} \mathrm{C}$ and $0.0035^{\circ} \mathrm{C}$ for $1 \%$ variation in moisture, and moisture's response intensity is $0.0638 \%, 0.0163 \%$ and $0.0050 \%$ for $1{ }^{\circ} \mathrm{C}$ variation in temperature at $10 \mathrm{~cm}, 30 \mathrm{~cm}$ and $90 \mathrm{~cm}$. Thirdly, the past value of soil moisture helps predict soil temperature at 10 $\mathrm{cm}, 30 \mathrm{~cm}$, and $90 \mathrm{~cm}$. Besides, the past value of soil temperature helps predict soil moisture at $10 \mathrm{~cm}$ and $30 \mathrm{~cm}$, but not at $90 \mathrm{~cm}$. We verified this model by using data from a different year and linking it to Soil Plant Atmospheric Continuum model.

\section{Introduction}

The hydrothermal conditions of a wheat-soil system are essential to the dynamic balance of heat, moisture and organic matter within the entire system and the thriving of wheat (Yang et al. 2012; Sun et al. 2018). Because of complicated biological, physical and chemical processes like soil respiration, soil evaporation, plant transpiration and so on, soil temperature and moisture have a close dynamic relationship with each other. Therefore, in order to better control and predict the hydrothermal conditions of a wheat-soil system, models simulating soil moisture-heat coupling need to be established (Perez et al. 2013; Whelan et al. 2015).

Most of the models employed to simulate moisture-heat coupling of soil are mechanistic models which call for complex parameters on soil properties and neglect time stochasticity. The following are some examples. Philip and de Vries (1957) took soil evaporation under different temperature into consideration and brought up the theory of moisture-gas-heat coupling transport under mass and energy balance. However, they did not consider the time lag effect and temporal heterogeneity. Based on the Philip model, Nassar and Horton (1989) used the water, heat, and salt transport equations which are based on Darcy's, Fourier's and Fick's laws to establish a model for the coupled transport of water, heat, and solute. But the model required a bunch of complicated parameters. Based on the theoretical integrity, Liu et al. (2005) established a model for describing the migration of heat, moisture, and gas in arid surface porous soil composed of a wet unsaturated layer and a dry but saturated layer. Bittelli et al. (2008) established a fully coupled numerical model to solve the governing equations for liquid water, water vapor and heat transfer in bare soil. Whelan et al. (2015) studied the impact of temperature and moisture on soil water repellency by designing and conducting experiments and factorial ANOVAs. However, the study fails to further explore characteristics like time lag and intensity of temperature and moisture's influence on each other. Lu and Dong (2015) set up a closed-formed equation for the thermal conductivity of unsaturated soils and shows that the soil water retention curve (SWRC) can be used to predict the thermal conductivity of sands. Striegl and Loheide (2012) developed a distributed soil moisture sensing system that addressed the difficulty of characterizing both spatial and temporal soil moisture dynamics at site scales. However, under wet conditions insensitivity of the instrument response curve adversely affected accuracy. Steele-Dunne et al. (2010) used distributed temperature sensing (DTS) to obtain simultaneous measurements of soil moisture over large areas, but they fail to address the complexity of 
56

57

58

59

60

61

62

63

64

65

66

67

deriving soil moisture due to the uncertainty and non-uniqueness in the relationship between thermal conductivity and soil moisture.

Most of the models mentioned above are deterministic. Since in reality soil moisture and soil temperature constantly vary with disturbances from an assortment of factors like weather and soil, stochastic models are more accurate in terms of prediction than deterministic models (Bolin et al. (in press)). Moreover, mechanistic models mentioned above require a lot of parameters which are difficult to obtain in some cases and some models can only be applied to a certain situation which is quite limited (Pan et al. 2018). In comparison, time series models prove to have a wider application since they can be easily established even if nothing but the hydrological time series data are in hand. In addition, although the hysteresis effect has been included in previous models like Soil Plant Atmospheric Continuum (SPAC), few indices have been established to quantify the lagging effect.

To take random variation into consideration, and to deal with the situation when only time series data are in hand, we designed a stochastic modeling technique for accurately analyzing moisture-heat coupling within a wheatsoil system. The model consists of three two-dimensional vector autoregression models, impulse response functions and Granger causality tests.

\section{Methods}

\section{Models}

\section{Vector Autoregression Model}

Vector autoregression model treats all variables as endogenous variables, accounting for Sims' critique that the exogeneity ${ }^{1}$ assumptions of some of the variables in simultaneous equations models are ad hoc and often not backed by fully developed theories. Impulse response analysis and Granger causality tests are tools which have been proposed for disentangling the relations between the variables in a vector autoregression model (Droumaguet et al. 2017; Bouri et al. 2018). The process of establishing a vector autoregression system is as follows.

First, we remove the seasonality of the time series $x_{t}, t=1,2, \ldots, n$. Seasonality in a time series is a regular pattern of changes that repeats over $S$ time periods, where $S$ defines the number of time periods until the pattern repeats again. In this case, $S=24$ (hours per day) is the span of the periodic seasonal behavior. Seasonal differencing is defined as a difference between a value and a value with lag that is a multiple of $S$. With $S=24$, a seasonal difference is $y_{t}=\left(1-B^{24}\right) x_{t}=x_{t}-x_{t-24}, t=25,26, \ldots, n$, where $B$ is the lag operator.

Next, we check the stationarity of the time series after seasonal adjustment, because average values of nonstationary time series cannot be used if the time period is not set since they are influenced by changes in time. A stochastic process is called stationary when the average and variance values are constant in the corresponding period and covariance values between any two time points depend not on the specific time point but on the lag between these two time points. The three conditions stated above for a time series $\left\{y_{t}\right\}$ to be stationary can be expressed in the following way:

$$
E\left(y_{t}\right)=\mu, \operatorname{Var}\left(y_{t}\right)=\sigma^{2}, \operatorname{Cov}\left(y_{t}, y_{t-k}\right)=\gamma_{k},
$$

where $\mu, \sigma^{2}$, and $\gamma$ are average, variance, and auto-covariance, respectively.

If the time series has a unit root, then it is not stationary. Under such circumstances, we restore the stationarity of the time series by making a difference of it. We use the Augmented Dickey-Fuller (ADF) test method to check the stationarity of the time series by testing whether the time series has a unit root. There are three model variants corresponding to three couples of hypothesis in the ADF test.

The first is an autoregressive model variant (referred to as $A R$ ), which specifies a test of the null model:

$$
H_{0}: y_{t}=y_{t-1}+\beta_{1} \Delta y_{t-1}+\beta_{2} \Delta y_{t-2}+\ldots+\beta_{p} \Delta y_{t-p}+\varepsilon_{t},
$$

against the alternative model:

\footnotetext{
${ }^{1}$ Exogenous variables are also called "input variables", thus "exogeneity" describes whether the variable is exogenous or not. An exogenous variable is completely determined by the external part of the system and are input into the system. It only affects the system and is not affected by the system.
} 


$$
H_{1}: y_{t}=\emptyset y_{t-1}+\beta_{1} \Delta y_{t-1}+\beta_{2} \Delta y_{t-2}+\ldots+\beta_{p} \Delta y_{t-p}+\varepsilon_{t} \text {, }
$$

96

97

98

99

100

101

102

103

104

105

106

107

108

109

110

111

112

113

114

115

116

117

118

119

120

121

122

123

124

125

126

with $\emptyset<1$, where $B_{1}, b_{2}, \ldots, b_{p}$ are regression coefficients, and $\varepsilon_{t}$ is the error term.

The second is an autoregressive model with drift variant (referred to as $A R D$ ), which specifies a test of the null model:

$$
H_{0}: y_{t}=y_{t-1}+\beta_{1} \Delta y_{t-1}+\beta_{2} \Delta y_{t-2}+\ldots+\beta_{p} \Delta y_{t-p}+\varepsilon_{t},
$$

against the alternative model:

$$
y_{t}=c+\emptyset y_{t-1}+\beta_{1} \Delta y_{t-1}+\beta_{2} \Delta y_{t-2}+\ldots+\beta_{p} \Delta y_{t-p}+\varepsilon_{t},
$$

with $\emptyset<1$, where $c$ is the constant term, $b_{1}, b_{2}, \ldots, b_{p}$ are regression coefficients, and $\varepsilon_{t}$ is the error term.

The third is a trend-stationary model variant (referred to as TS), which specifies a test of the null model:

$$
H_{0}: y_{t}=c+y_{t-1}+\beta_{1} \Delta y_{t-1}+\beta_{2} \Delta y_{t-2}+\ldots+\beta_{p} \Delta y_{t-p}+\varepsilon_{t},
$$

against the alternative model:

$$
H_{1}: y_{t}=c+\delta t+\emptyset y_{t-1}+\beta_{1} \Delta y_{t-1}+\beta_{2} \Delta y_{t-2}+\ldots+\beta_{p} \Delta y_{t-p}+\varepsilon_{t},
$$

with $\emptyset<1$, where $c$ is the constant term, $\delta$ is the coefficient of the trend term, $B_{1}, B_{2}, \ldots, B_{p}$ are regression coefficients, and $\varepsilon_{t}$ is the error term (Chen et al. 2018).

Then, we have to determine the optimal lag order for the vector autoregression model. The proper selection of lag is important because long lag structures reduce the error term's correlation yet they may lack efficiency. We use the estimators AIC (Akaike information criterion) and BIC (Bayesian information criterion), both of which are founded on information theory and estimate relative goodness of fit of given models, as standards of choosing the optimal lag of the vector autoregression model (Mao et al. 2018).

AIC value of a model is calculated as follows:

$$
A I C=2 k-2 \ln (\hat{L}),
$$

where $k$ is the number of estimated parameters in the model and $\hat{L}$ is the maximum value of the likelihood function for the model.

BIC value of a model is calculated as follows:

$$
B I C=\ln (n) k-2 \ln (\hat{L}),
$$

where $n$ is the number of data points in $\mathrm{x}$ or the number of observations.

When fitting the models, it is possible to increase the simulation accuracy by adding parameters, but doing so may result in overfitting. Both $\mathrm{BIC}$ and $\mathrm{AIC}$ attempt to solve this problem by introducing a penalty term for the number of parameters in the model. And the lag order corresponding to the lowest AIC value or BIC value is taken as the optimal lag order. We use maximum likelihood estimation ${ }^{2}$ to estimate the model parameters.

The stability test of the established model is required because if the model is unstable, some results will not be valid (such as the standard error of the impulse response function). In this paper, we use the AR root test and if all the roots of the vector autoregression model estimated based on empirical data have a reciprocal of less than 1 (that is, if they are within the unit circle), they are stable.

The way to check whether a vector autoregression model is stationary is as follow. For vector autoregression model

$$
\left(y_{t}-\mu\right)=\phi_{1}\left(y_{t-1}-\mu\right)+\phi_{2}\left(y_{t-2}-\mu\right)+\ldots+\phi_{p}\left(y_{t-p}-\mu\right)+\varepsilon_{t}
$$

where $y_{t}$ is a vector in $\mathrm{R}^{\mathrm{n}}$, we first write it in the form of deviation. Then we define matrix $\mathrm{F}$ :

2 The method of maximum likelihood is based on the likelihood function. Suppose we are given a family of distributions $\{f(\because \theta) \mid \theta \in \Theta\}$, where $\theta$ denotes the parameters (possibly multi-dimensional) for the model. The method defines a maximum likelihood estimate: $\hat{\theta} \in\{\underset{\theta \in \Theta}{\operatorname{argmax}} \mathcal{L}(\theta ; x)\}$, where $\mathcal{L}(\theta ; x)$ denotes the likelihood function, because intuitively this selects parameter values that make the data most probable.

Peer) reviewing PDF | (2018:12:33376:6:0:NEW 1 May 2019) 


$$
F=\left[\begin{array}{cccccc}
\phi_{1} & \phi_{2} & \phi_{3} & \cdots & \phi_{p-1} & \phi_{p} \\
I_{n} & 0 & 0 & \cdots & 0 & 0 \\
0 & I_{n} & 0 & \cdots & 0 & 0 \\
\vdots & \vdots & \vdots & \cdots & \vdots & \vdots \\
0 & 0 & 0 & \cdots & I_{n} & 0
\end{array}\right]
$$

128

129

130

Then we write it in the standard form as follow.

$$
\left[\begin{array}{l}
y_{t} \\
z_{t}
\end{array}\right]=\left[\begin{array}{l}
a_{10} \\
a_{20}
\end{array}\right]+\left[\begin{array}{ll}
a_{11} & a_{12} \\
a_{21} & a_{22}
\end{array}\right]\left[\begin{array}{l}
y_{t-1} \\
z_{t-1}
\end{array}\right]+\left[\begin{array}{l}
e_{1 t} \\
e_{2 t}
\end{array}\right]
$$

137

Moreover, we can write it in the following form if the vector autoregression model is stable.

$$
\left[\begin{array}{l}
y_{t} \\
z_{t}
\end{array}\right]=\left[\begin{array}{l}
\bar{y}_{t} \\
\bar{z}_{t}
\end{array}\right]+\sum_{i=0}^{\infty}\left[\begin{array}{ll}
a_{11} & a_{12} \\
a_{21} & a_{22}
\end{array}\right] i\left[\begin{array}{l}
e_{1 t-i} \\
e_{2 t-i}
\end{array}\right]
$$

138

For the transformation from (10) to (11), the error term can be transformed as follow.

$$
\left[\begin{array}{l}
e_{1 t} \\
e_{2 t}
\end{array}\right]=1 /\left(1-b_{12} b_{21}\right)\left[\begin{array}{cc}
1 & -b_{12} \\
-b_{21} & 1
\end{array}\right]\left[\begin{array}{c}
\varepsilon_{y t} \\
\varepsilon_{z t}
\end{array}\right],
$$

139

By combining equation (12) and (13), we obtain

$$
\left[\begin{array}{l}
y_{t} \\
z_{t}
\end{array}\right]=\left[\begin{array}{l}
\bar{y}_{t} \\
z_{t}
\end{array}\right]+1 /\left(1-b_{12} b_{21}\right) \sum_{i=0}^{\infty}\left[\begin{array}{ll}
a_{11} & a_{12} \\
a_{21} & a_{22}
\end{array}\right] i\left[\begin{array}{cc}
1 & -b_{12} \\
-b_{21} & 1
\end{array}\right]\left[\begin{array}{l}
\varepsilon_{y t-i} \\
\varepsilon_{z t-i}
\end{array}\right],
$$

140 In order to simplify the equation, we define matrix $\phi_{i}$, and denote its elements as $\phi_{j k}(i)$.

$$
\phi_{i}=A_{1}^{\mathrm{i}} /\left(1-b_{12} b_{21}\right)\left[\begin{array}{cc}
1 & -b_{12} \\
-b_{21} & 1
\end{array}\right]
$$

141 Thus, the moving average of the equation (11) and (12) can be expressed as

$$
\left[\begin{array}{l}
y_{t} \\
z_{t}
\end{array}\right]=\left[\begin{array}{l}
\bar{y}_{t} \\
\bar{z}_{t}
\end{array}\right]+\sum_{i=0}^{\infty}\left[\begin{array}{ll}
\phi_{11}(i) & \phi_{12}(i) \\
\phi_{21}(i) & \phi_{22}(i)
\end{array}\right]\left[\begin{array}{c}
\varepsilon_{y t-i} \\
\varepsilon_{z t-i}
\end{array}\right]
$$

Moving average is a useful tool for studying the mutual influence between the two series $\left\{y_{t}\right\}$ and $\left\{z_{t}\right\}$, for the impulse response function of $\left\{y_{t}\right\}$ and $\left\{z_{t}\right\}$ to one unit shock of $\varepsilon_{y t}$ and $\varepsilon_{z t}$ can be built using the coefficients of $\phi_{i}$. Here $\phi_{11}(i), \phi_{12}(i), \phi_{21}(i)$ and $\phi_{22}(i)$ are called impulse response functions. And the graphs of these functions show the impulse response of the time series to one unit of positive shock.

To be more specific, coefficient $\phi_{12}(0)$ indicates the current impact of one unit positive change in $\varepsilon_{z t}$ have on $y_{t}$. Similarly, after one period of calibration, $\phi_{11}(1)$ and $\phi_{12}(1)$ also denote the impact of one unit positive change 148 in $\varepsilon_{y t}$ and $\varepsilon_{z t}$ have on $y_{t+1}$. The cumulative effect of $\varepsilon_{y t}$ and $\varepsilon_{z t}$ 's unit impulse response can be obtained by the 149 
$150 \varepsilon_{z t}$ on $y_{t+n}$ is $\phi_{12}(n)$. Therefore, after $n$ periods the accumulative impact of $\varepsilon_{z t}$ on $y_{t}$ is $\sum_{i=0}^{n} \phi_{12}(i)$. If $n$ tends to

151 be positive infinite, the accumulative effect can be obtained. Since we have assumed that $y_{t}$ and $z_{t}$ are stationary, 152 when $j$ and $k$ approximate infinite, the value of $\phi_{j k}(i)$ is 0 . Since all parameters of the vector autoregression system 153 can be calculated, it is totally possible to track every value of $\varepsilon_{y t}$ and $\varepsilon_{z t}$ 's impact on $\left\{y_{t}\right\}$ and $\left\{z_{t}\right\}$ can be calculated. 154 The time when $\phi_{j k}(i)$ approximates 0 is the time lag of impulse response, and the gap between the positive largest 155 value and negative largest value of $\phi_{j k}(i)$ can be used to describe the intensity of the impulse response.

156

157

158

159

160

161

162

163

164

165

166

167

168

169

170

171

172

173

174

175

176

177

178

179

180

181

182

183

184

185

Granger Causality Test

The Granger causality test is used to test if the variable y can be used to predict the variable $x$. That is when the variable $\mathrm{x}$ is regressed according to the past value of the variable $\mathrm{y}$, the explanatory ability of the regression can be significantly enhanced. It should be noted that two variables have a temporal "causal relationship" but do not necessarily have a logical causal relationship.

In an attempt to test whether past values of $y$ help predict $x$, we first perform an ordinary least squares (OLS) estimation:

$$
x_{t}=c_{1}+a_{1} x_{t-1}+a_{2} x_{t-2}+\cdots+a_{p} x_{t-p}+b_{1} y_{t-1}+b_{2} y_{t-2}+\cdots+b_{p} x_{t-p}+u_{t},
$$

And we propose the null hypothesis:

$$
H_{0}: b_{1}=b_{2}=\cdots=b_{p}=0 \text {, }
$$

which means that $\mathrm{y}$ is not the Granger reason for $\mathrm{x}$. To conduct an F-test for this hypothesis, first, we estimate the equation without restriction $H_{0}$, and obtain the sum of residual:

$$
R S S_{0}=\sum_{t=1}^{T} \hat{u}_{t}^{2}
$$

Then, we estimate the equation with restriction $H_{0}$, and obtain the sum of residual:

$$
R S S_{1}=\sum_{t=1}^{T} \hat{e}_{t}^{2}
$$

We build the F statistic using the expression below:

$$
\frac{\left(R S S_{1}-R S S_{0}\right) / p}{R S S_{0} /(T-2 p-1)} \sim F(p, T-2 p-1),
$$

where $T$ is the size of the sample. Based on the data, if the value of $F$ statistic is higher than the critical value, then we reject the null hypothesis and admit that increasing the lag order of y can significantly improve the explanatory ability of the model. Under such circumstances, we say that the past value of y helps predict x (Stokes \& Purdon 2018).

\section{Stochastic Model System for Soil Moisture-heat Coupling}

First, we build three vector autoregression models at the depth of $10 \mathrm{~cm}, 30 \mathrm{~cm}$, and $90 \mathrm{~cm}$. We choose these three depths because, during the greening period which is around $15^{\text {th }}$ March, the diameter of wheat root reaches its maximum approximately at the depth of $10 \mathrm{~cm}, 30 \mathrm{~cm}$, and $90 \mathrm{~cm}$, respectively, thus resulting in more water absorption at these three depths. In addition, usually, the soil is divided into topsoil, subsoil, and substratum, the representative depths of which approximate $10 \mathrm{~cm}, 30 \mathrm{~cm}$, and $90 \mathrm{~cm}$. In addition, we select hourly data on soil moisture and temperature from December to May because this period covers the main growing stages of winter wheat. This time period can be adjusted according to the growing stages of different wheat species (Awad et al. 2018).

Second, we build six impulse response functions for these three vector autoregression systems. Based on the results of impulse response function analysis, we are able to obtain the time lag and intensity of impulse response. For example, if one unit of positive shock is given to soil temperature at the depth of $10 \mathrm{~cm}$, we calculate the time length during which obvious deviation from zero can be seen in soil moisture's response to $1^{\circ} \mathrm{C}$ of positive variation. This provides us with information on how long soil moisture will be influenced if there is a sudden change in

PeerJ reviewing PDF | (2018:12:33376:6:0:NEW 1 May 2019) 
186 temperature. In addition, the gap between the highest point and lowest point of the response is the intensity of impulse response. The larger the intensity, the stronger the influence of soil temperature has on moisture.

Third, we conduct six Granger causality tests between two variables of soil moisture and temperature at three depths. According to the result of the Granger causality test, we are able to decide a more proper way of forecasting soil moisture and temperature by taking the Granger causal relationship of moisture and temperature into consideration. If, for example, at the depth of $10 \mathrm{~cm}$ the past value of soil temperature helps predict soil moisture, it means that the past value of soil temperature influences soil moisture. Therefore, when establishing empirical models forecasting soil moisture, we should choose the ARMAX model which is an ARMA model with an exogenous variable in an attempt to take into consideration of temperature's influence on moisture. On the other hand, if the past value of soil temperature does not help predict soil moisture, it means that the past value of soil temperature does not have a significant influence on soil moisture. If soil temperature and moisture are Granger reasons for each other, it suggests that the present value of two variables are related to each other's past value. Thus, a vector autoregression model treating all variables as endogenous variables will be the optimal choice.

\section{Field experiment on soil moisture and temperature}

The experiment on the wheat of Bainong Dwarf Anti-floating No.58 ${ }^{3}$ was carried out at Shangqiu Experimental Station of Farmland Irrigation Institute of Chinese Academy of Agricultural Sciences with a latitude of $34^{\circ} 35.222^{\prime} \mathrm{N}$, longitude of $115^{\circ} 34.515^{\prime} \mathrm{E}$, and elevation of $55.6 \mathrm{~m}$. The average annual temperature there is $13.9^{\circ} \mathrm{C}$, and the frostfree period is $180 \mathrm{~d}$ to $230 \mathrm{~d}$. In addition, the average annual precipitation is $708 \mathrm{~mm}$ with the precipitation from July to September accounting for $65 \% \sim 75 \%$ of the total annual precipitation, and the average annual evaporation being $1735 \mathrm{~mm}$. The soil of the test site is a loam, which refers to soil consists of clay (30\% 40\%), silt (30\% 40\%), and sand $(30 \% \sim 40 \%)$.

The Irrigation method adopted is drip irrigation at the depth of $30 \mathrm{~cm}$ under soil surface. The sensor we used for soil water monitoring is called "Soil-Water", which was produced in Australia. The basic components of this soil monitoring system are data collectors, solar modules, mounting components, and soil sensors. The accuracy for temperature is $<0.1^{\circ} \mathrm{C}$, and but the accuracy of soil moisture sensor was not provided by the manufacturer. We installed the instrument probes of the moisture meter at the depth of $10,20,30,40,50,60,70,80,90$ and $100 \mathrm{~cm}$, and measured soil moisture and soil temperature at these depths simultaneously. The instrument's temperature measurement range is from $-20^{\circ} \mathrm{C}$ to $60^{\circ} \mathrm{C}$.

Among these ten sets of data, we select hourly data on soil moisture and soil temperature from December $19^{\text {th }}$, 2017 to May 30th, 2018 at the depth of $10 \mathrm{~cm}, 30 \mathrm{~cm}$ and $90 \mathrm{~cm}$, which is in accordance with the model designed above. In addition, the selection of the measurement interval takes into account both the memory capacity of the instrument and the minimum scale of moisture transport, since one-hour interval is sufficient to show the footprint of water movement.

\section{Results}

Figure 1 shows data on soil moisture and temperature measured at the depth of 10, 20,30,40,50,60,70, 80, 90 and $100 \mathrm{~cm}$. We can see that both soil temperature and soil moisture content exhibits periodical variations within a day and trends changing with the alternation of seasons. Soil temperature decreases with the cooling trend of climate from December to January and increases with the overall warming of the climate from February to May in next year. Soil moisture content, however, experiences a sudden hike around $2^{\text {nd }}$ March and $19^{\text {th }}$ March from $10 \mathrm{~cm}$ to $50 \mathrm{~cm}$ due to irrigation, and gradually decreases from March to May due to evapotranspiration, indicating an active water absorption process of winter wheat root system. Soil moisture content exhibits obvious differences among different depths.

Figure 1. Soil moisture (a) and temperature (b) at different depths.

\footnotetext{
${ }^{3}$ Bainong Dwarf Anti-floating No.58 is a new epoch-making wheat variety developed in 2003 by the Wheat Breeding Center in Henan University of Science and Technology. This variety belongs to the semi-winter mid-maturing variety. The plant height is about $70 \mathrm{~cm}$, with high resistance to lodging and good fullness. It has high resistance to powdery mildew, stripe rust, leaf blight, and medium resistance to sheath blight, strong root activity, good ripening, and yellowing. It also has the preponderance of high yield with the average yield being $7500-8250 \mathrm{~kg} / \mathrm{ha}$ and the maximum being $10500 \mathrm{~kg} / \mathrm{ha}$.
}

Peer] reviewing PDF | (2018:12:33376:6:0:NEW 1 May 2019) 
We use hourly data from December $19^{\text {th }}, 2017$ to May $30^{\text {th }}, 2018$ on soil moisture content at the soil depths of $10 \mathrm{~cm}, 30 \mathrm{~cm}$ and $90 \mathrm{~cm}$ (hereinafter referred to as MC10, MC30 and MC90, respectively), soil temperature at the depth of $10 \mathrm{~cm}, 30 \mathrm{~cm}$ and $90 \mathrm{~cm}$ (hereinafter referred to as ST10, ST30 and ST9O, respectively).

First, we remove the seasonality of the time series of MC10, ST10, MC30, ST30, MC90 and ST90, since it is known from the above figures that the six hourly time series have obvious diurnal pattern due to the periodical variations of meteorological factors, evapotranspiration, and root water uptake within a day, especially in shallow layers. After seasonal difference, the period of the data is from December $20^{\text {th }}, 2017$ to $\mathrm{May} 30^{\text {th }}, 2018$. The corresponding time series of the six detrended variables are referred to as MCSD10, STSD10, MCSD30, STSD30, MCSD90, and STSD90, respectively (Figure 2).

Table 1. Unit root test results of the deseasonalized soil moisture and temperature series.

${ }^{1} T$ stat. is the t-statistic for performing the ADF test. ${ }^{2}$ Model indicates the type of hypothesis selected and the lag period which is added to make the residual become white noise. ${ }^{3} P$-Value represents the corresponding $p$-value. ${ }^{4} C . V$. indicates critical value. ${ }^{5}$ * indicates a significant level of $10 \%, * *$ indicates a significant level of $5 \%$, and *** indicates a significant level of $1 \%$. ${ }^{6}$ Stationary indicates that the time series is stable.

Figure 2. Deseasonalized soil temperature (a) and moisture (b) at the depth of $10 \mathrm{~cm}, 30 \mathrm{~cm}$, and $90 \mathrm{~cm}$.

According to the above results of the ADF test (Table 1), the variables of MCSD10, STSD10, MCSD30, STSD30, and MCSD90 are all stationary under the significance level of 0.01 . The variable of STSD90 is stationary under the significance level of 0.05 . Thus, it is appropriate to use the variables of MCSD10, STSD10, MCSD30, STSD30, MCSD90 and STSD9O to build vector autoregression models since they are all stationary.

\section{Vector Autoregression Model Establishment}

The values of AIC and BIC for vector autoregression models of different lags are calculated (Table 2) to determine the optimal lag orders for the vector autoregression models.

Table 2. Calculated $\ln (\hat{L}), \mathrm{AIC}$ and $\mathrm{BIC}$ for vector autoregression model of different lags at the depth of $10 \mathrm{~cm}, 30$ $\mathrm{cm}$, and $90 \mathrm{~cm}$.

For soil depth of $10 \mathrm{~cm}$, among the eight lag orders, lag order 8 has the lowest AIC value and lag order 5 has the lowest BIC value. Since model with a lag order of 5 has fewer parameters to estimate which leads to smaller estimation error for the whole model, we choose 5 as the optimal lag order (Table 2). Based on the optimal lag structure and the time series of MCSD10 and STSD10, we estimate the parameters of the vector autoregression model using maximum likelihood estimation. Most of the t-statistic of the estimated coefficients in the above regression model is significant at the $10 \%$ significance level. Although some of the coefficients are not significant, it may because multiple hysteresis values with the same variables in the same equation result in multiple collinearities. Thus, finally, we obtained the estimated vector autoregression model:

$$
\begin{gathered}
{\left[\begin{array}{c}
M C S D 10_{t} \\
S T S D 10_{t}
\end{array}\right]=\left[\begin{array}{c}
-0.002 \\
0.005
\end{array}\right]+\left[\begin{array}{cc}
1.593 & -0.026 \\
0.167 & 1.754
\end{array}\right]\left[\begin{array}{c}
M C S D 10_{t-1} \\
S T S D 10_{t-1}
\end{array}\right]+\left[\begin{array}{cc}
-0.631 & 0.019 \\
-0.205 & -0.816
\end{array}\right]\left[\begin{array}{c}
M C S D 10_{t-2} \\
S T S D 10_{t-2}
\end{array}\right]} \\
+\left[\begin{array}{cc}
0.274 & 0.012 \\
-0.061 & 0.026
\end{array}\right]\left[\begin{array}{c}
M C S D 10_{t-3} \\
S T S D 10_{t-3}
\end{array}\right]+\left[\begin{array}{cc}
-0.526 & 0.024 \\
0.094 & -0.060
\end{array}\right]\left[\begin{array}{c}
M C S D 10_{t-4} \\
S T S D 10_{t-4}
\end{array}\right]+\left[\begin{array}{cc}
0.257 & -0.031 \\
0.008 & 0.068
\end{array}\right] \\
{\left[\begin{array}{c}
M C S D 10_{t-5} \\
S T S D 10_{t-5}
\end{array}\right]+\left[\begin{array}{l}
u_{1 \mathrm{t}} \\
u_{2 t}
\end{array}\right]}
\end{gathered}
$$

For soil depth of $30 \mathrm{~cm}$, Among the eight lag orders, lag order 8 has the lowest AIC value and the lowest BIC value. Thus, we choose 8 as the optimal lag order and build a vector autoregression model (Table 2). We obtained the estimated vector autoregression model as follow: 


$$
\begin{gathered}
{\left[\begin{array}{c}
M C S D 30_{\mathrm{t}} \\
S T S D 30_{t}
\end{array}\right]=\left[\begin{array}{c}
-0.002 \\
0.001
\end{array}\right]+\left[\begin{array}{cc}
1.182 & 0.117 \\
-0.006 & 0.559
\end{array}\right]\left[\begin{array}{cc}
M C S D 30_{t-1} \\
S T S D 30_{t-1}
\end{array}\right]+\left[\begin{array}{cc}
-0.173 & -0.090 \\
-0.022 & 0.344
\end{array}\right]\left[\begin{array}{c}
M C S D 30_{t-2} \\
S T S D 30_{t-2}
\end{array}\right]} \\
+\left[\begin{array}{cc}
-0.016 & 0.020 \\
0.042 & 0.228
\end{array}\right]\left[\begin{array}{cc}
M C S D 30_{t-3} \\
S T S D 30_{t-3}
\end{array}\right]+\left[\begin{array}{cc}
-0.002 & -0.054 \\
-0.003 & 0.149
\end{array}\right]\left[\begin{array}{l}
M C S D 30_{t-4} \\
S T S D 30_{t-4}
\end{array}\right]+\left[\begin{array}{cc}
0.000 & 0.013 \\
-0.022 & 0.012
\end{array}\right] \\
{\left[\begin{array}{c}
M C S D 30_{t-5} \\
S T S D 30_{t-5}
\end{array}\right]+\left[\begin{array}{cc}
-0.006 & -0.014 \\
0.019 & -0.074
\end{array}\right]\left[\begin{array}{l}
M C S D 30_{t-6} \\
S T S D 30_{t-6}
\end{array}\right]+\left[\begin{array}{cc}
0.012 & 0.040 \\
-0.010 & -0.082
\end{array}\right]\left[\begin{array}{l}
M C S D 30_{t-7} \\
S T S D 30_{t-7}
\end{array}\right]+} \\
{\left[\begin{array}{ll}
-0.027 & -0.029 \\
-0.002 & -0.148
\end{array}\right]\left[\begin{array}{l}
M C S D 30_{t-8} \\
S T S D 30_{t-8}
\end{array}\right]+\left[\begin{array}{l}
u_{1 \mathrm{t}} \\
u_{2 t}
\end{array}\right]}
\end{gathered}
$$

For soil depth of $90 \mathrm{~cm}$, Among the eight lag orders, lag order 8 has the lowest AIC value and lag order 7 has the lowest BIC value. Since model with a lag order of 7 has fewer parameters to estimate which leads to smaller estimation error for the whole model, we choose 7 as the optimal lag order (Table 2). We obtained the estimated vector autoregression model as follow:

$$
\begin{aligned}
& {\left[\begin{array}{l}
M^{M C S D} 90_{\mathrm{t}} \\
S T S D 90_{t}
\end{array}\right]=\left[\begin{array}{ll}
0.690 & 0.058 \\
0.133 & 0.345
\end{array}\right]\left[\begin{array}{l}
M C S D 90_{t-1} \\
S T S D 90_{t-1}
\end{array}\right]+\left[\begin{array}{ll}
0.336 & 0.025 \\
0.026 & 0.200
\end{array}\right]\left[\begin{array}{l}
M C S D 90_{t-2} \\
S T S D 90_{t-2}
\end{array}\right]+} \\
& {\left[\begin{array}{cc}
0.130 & -0.001 \\
0.045 & 0.191
\end{array}\right]\left[\begin{array}{cc}
M C S D 90_{t-3} \\
S T S D 90_{t-3}
\end{array}\right]+\left[\begin{array}{cc}
-0.024 & -0.010 \\
0.079 & 0.103
\end{array}\right]\left[\begin{array}{cc}
M C S D 90_{t-4} \\
S T S D 90_{t-4}
\end{array}\right]+\left[\begin{array}{cc}
-0.061 & -0.031 \\
-0.166 & 0.039
\end{array}\right]} \\
& {\left[\begin{array}{cc}
M C S D 90_{t-5} \\
S T S D 90_{t-5}
\end{array}\right]+\left[\begin{array}{cc}
-0.004 & -0.008 \\
-0.132 & 0.056
\end{array}\right]\left[\begin{array}{cc}
M C S D 90_{t-6} \\
S T S D 90_{t-6}
\end{array}\right]+\left[\begin{array}{cc}
-0.071 & -0.032 \\
0.011 & 0.058
\end{array}\right]\left[\begin{array}{c}
M C S D 90_{t-7} \\
S T S D 90_{t-7}
\end{array}\right]+\left[\begin{array}{l}
u_{1 t} \\
u_{2 t}
\end{array}\right]}
\end{aligned}
$$

Then we check the stability of these three vector autoregression models. Figure 3 shows that all unit roots fall within the unit root circle, so it is reasonable to believe that the vector autoregression models at these three soil depths are stable, indicating that there is a long-term stable relationship between the variables selected which can be further analyzed.

Figure 3. Inverse roots of AR characteristic polynomial at $10 \mathrm{~cm}(\mathrm{a}), 30 \mathrm{~cm}(\mathrm{~b})$ and $90 \mathrm{~cm}(\mathrm{c})$.

\section{Impulse Response Function Analysis}

The impulse response results at three different depths are shown in Table 3.

Table 3. Impulse response results of MCSD10, STSD10, MCSD30, STSD30, MCSD90 and STSD90.

${ }^{1} \mathrm{RP}$ represents retrospective periods, its unit is an hour.

The impulse response diagrams at three different depths are shown in Figure 4. The horizontal axis represents the number of retrospective periods from $0 \mathrm{~h}$ to $120 \mathrm{~h}$, while the vertical axis represents the response of the dependent variable to the shock. The confidence interval is used because the vector autoregression model coefficients have some error in the estimation. Setting the confidence interval can accommodate the inherent uncertainty of the parameters.

Figure 4. Impulse response of MCSD10 to shock in STSD10 (a), impulse response of STSD10 to shock in MCSD10 (b), impulse response of MCSD30 to shock in STSD30 (c), impulse response of STSD30 to shock in MCSD30 (d), impulse response of $M C S D 90$ to shock in STSD90 (e), impulse response of STSD90 to shock in MCSD 90 (f). The solid line of blue fluorescence represents the impulse response and the red dashed line represents the confidence interval of the impulse response with a confidence level of 0.90 .

Peer) reviewing PDF | (2018:12:33376:6:0:NEW 1 May 2019) 
291

292

293

294

295

296

297

298

299

300

301

302

303

304

305

306

307

308

309

310

311

312

313

314

315

316

317

318

319

320

321

322

323

324

325

326

327

328

329

330

331

332

333

334

335

336

337

When STSD10 is given one unit of positive shock, MCSD10 reacts to $0.0312 \%$ in the current period, and then monotonically increases until it reaches a positive maximum of $0.0638 \%$ in the ninth period. And then it gradually decreases and falls near zero in the long run indicating that the vector autoregression system is stable. It can be seen that the impact of STSD10 on MCSD10 has a lagging effect since its impulse response is only close to zero after around 25 periods. Moreover, the intensity of the influence which can be quantified as $0.0638 \%$ is relatively high (Figure 4. (a)).

When MCSD10 is given one unit of positive shock, STSD10 reacts to $0.0453^{\circ} \mathrm{C}$ in the current period, and then monotonically increases until it reaches a positive maximum of $0.2004^{\circ} \mathrm{C}$ in the fourth period. And then it gradually decreases, and fall near zero in the long run indicating that the vector autoregression system is stable. It can be seen that the impact of MCSD10 on STSD10 has a lagging effect since its impulse response never falls below zero and is only close to zero after 50 periods. Moreover, the intensity of the influence which can be quantified as $0.2004^{\circ} \mathrm{C}$ is quite high (Figure 4. (b)).

When STSD30 is given one unit of positive shock, MCSD30 reacts to $-0.0077 \%$ in the current period, and then monotonically increases until it reaches a positive maximum of $0.0086 \%$ in the $22^{\text {nd }}, 23^{\text {rd }}, 24^{\text {th }}$ period. And then it gradually decreases and falls near zero in the long run indicating that the vector autoregression system is stable. Besides, the impact of STSD30 on MCSD30 has a lagging effect based on the fact that it is only close to zero after around 50 periods. Moreover, the intensity of the influence which can be quantified as $0.0163 \%$ is lower than the intensity of MCSD10's response to STSD10 (Figure 4. (c)).

When MCSD30 is given one unit of positive shock, STSD 30 reacts to $-0.0045^{\circ} \mathrm{C}$ in the current period, and then monotonically decreases until it reaches a negative maximum of $-0.0163^{\circ} \mathrm{C}$ at the $36^{\text {th }}, 37^{\text {th }}, 38^{\text {th }}, 39^{\text {th }}$ period. And then it gradually increases, and fall near zero in the long run indicating that the vector autoregression system is stable. It can be seen that the impact of MCSD30 on STSD30 has a lagging effect since its impulse response is only close to zero after the $120^{\text {th }}$ period. Moreover, the intensity of the influence which can be quantified as $0.0163^{\circ} \mathrm{C}$ is lower than the intensity of STSD10's response to MCSD10 (Figure 4. (d)).

When STSD90 is given one unit of positive shock, MCSD90 reacts to $-0.0033 \%$ in the current period, and then monotonically increases until it reaches a positive maximum of $0.0017 \%$ from the $17^{\text {th }}$ to $30^{\text {th }}$ period. And then it gradually decreases and falls near zero in the long run indicating that the vector autoregression system is stable. It can be seen that the impact of STSD90 on MCSD90 has a lagging effect based on the fact that it is only close to zero after 120 periods. Moreover, the intensity of the influence which can be quantified as $0.0050 \%$ is lower than the intensity of MCSD30's response to STSD30 (Figure 4. (e)).

When MCSD90 is given one unit of positive shock, STSD90 reacts to $-0.0107^{\circ} \mathrm{C}$ in the current period, and then monotonically increases and reaches a relatively stable value of $-0.0035^{\circ} \mathrm{C}$ at around the $120^{\text {th }}$ period. It can be seen that the impact of MCSD90 on STSD90 has a lagging effect. Moreover, the intensity of the influence which can be quantified as $0.0035^{\circ} \mathrm{C}$ is lower than the intensity of STSD30's response to MCSD30 (Figure 4. (f)).

\section{Granger Causality Test}

By carrying out Granger causality test, we figured out whether the past value of STSD10 (STSD30, STSD90) helps predict MCSD10 (MCSD30, MCSD90) and whether the past value of MCSD10 (MCSD30, MCSD90) helps predict STSD10 (STSD30, STSD90).

From the results in Table 4 and Table 5, it is known that the past value of MCSD10 helps predict STSD10, but the past value of STSD10 does not help predict MCSD10. This means that the past value of soil moisture content is helpful in terms of predicting the present value of soil temperature at the depth of $10 \mathrm{~cm}$, while soil temperature has a small influence in terms of predicting soil moisture content at the depth of $10 \mathrm{~cm}$. Besides, the results also indicate soil moisture content varies ahead of soil temperature.

From Table 6 and Table 7, we can see that at the significance level of 0.05 and 0.10 , the past value of MCSD30 helps predict STSD30 and the past value of STSD30 helps predict MCSD30. This suggests that the past value of soil moisture content is helpful in terms of predicting the present value of soil temperature at the depth of $30 \mathrm{~cm}$, and the past value of soil temperature is helpful in terms of predicting the present value of soil moisture content at the depth of $30 \mathrm{~cm}$.

From Table 8 and Table 9, we can see that at the significance level of $0.01,0.05$ and 0.10 , the past value of MCSD90 helps predict STSD90 and the past value of STSD90 helps predict MCSD90. This suggests that the past value of soil moisture content is helpful in terms of predicting the present value of soil temperature at the depth of $90 \mathrm{~cm}$,

Peer) reviewing PDF | (2018:12:33376:6:0:NEW 1 May 2019) 
338

339

340

341

342

343

344

345

346

347

348

349

350

351

352

353

354

355

356

357

358

359

360

361

362

363

364

365

366

367

368

369

370

371

372

373

374

375

376

377

378

379 and the past value of soil temperature is helpful in terms of predicting the present value of soil moisture content at the depth of $90 \mathrm{~cm}$.

Table 4. Granger causality test determining whether STSD10 helps predict MCSD10.

Table 5. Granger causality test determining whether MCSD10 helps predict STSD10.

Table 6. Granger causality test determining whether STSD30 helps predict MCSD30.

Table 7. Granger causality test determining whether MCSD30 helps predict STSD30.

Table 8. Granger causality test determining whether STSD90 helps predict MCSD90.

Table 9. Granger causality test determining whether MCSD90 helps predict STSD90.

\section{Discussions}

Specific results

Firstly, the time lag of soil temperature's response to shock in soil moisture is about $25 \mathrm{~h}$ at $10 \mathrm{~cm}, 50 \mathrm{~h}$ at 30 $\mathrm{cm}$, and $120 \mathrm{~h}$ at $90 \mathrm{~cm}$, while the time lag of soil moisture's response to shock in soil temperature is for about $50 \mathrm{~h}$ at $10 \mathrm{~cm}$ and longer than $120 \mathrm{~h}$ at $30 \mathrm{~cm}$ and $90 \mathrm{~cm}$.

Secondly, the intensity of soil temperature's impulse response to shock in soil moisture decreases from $0.2004^{\circ} \mathrm{C}$ at the depth of $10 \mathrm{~cm}$, to $0.0163^{\circ} \mathrm{C}$ at the depth of $30 \mathrm{~cm}$, and finally to $0.0035^{\circ} \mathrm{C}$ at the depth of $90 \mathrm{~cm}$. Similarly, the intensity of soil moisture's impulse response to soil temperature also decreases from $0.0638 \%$ at the depth of $10 \mathrm{~cm}$, to $0.0163 \%$ at the depth of $30 \mathrm{~cm}$, and finally to $0.0050 \%$ at the depth of $90 \mathrm{~cm}$.

Thirdly, soil moisture is the Granger reason of soil temperature at the depth of $10 \mathrm{~cm}, 30 \mathrm{~cm}$, and $90 \mathrm{~cm}$. This means that the past value of soil moisture is helpful in terms of predicting the present value of soil temperature, and probably is the actual logical reason for changes in soil temperature. However, the causal relationship does not necessarily mean that there exists a direct connection between soil temperature and moisture, since a series of physical and biological processes may complicate the relations between soil temperature and moisture. While soil temperature does not help predict soil moisture at the depth of $10 \mathrm{~cm}$, it helps predict soil moisture at the depth of $30 \mathrm{~cm}$ and $90 \mathrm{~cm}$. Therefore, according to the basic principles of Granger causality test, when predicting the dynamic variation of soil temperature and moisture at the depth of $30 \mathrm{~cm}$ and $90 \mathrm{~cm}$, the other variable's past values should be taken into consideration, which means that a vector autoregression model may be a better choice. In comparison, at the depth of $10 \mathrm{~cm}$, the past value of soil temperature is not helpful for predicting the present value of soil moisture. However, it may be more accurate to incorporate soil moisture as an exogenous variable when predicting soil temperature at $10 \mathrm{~cm}$.

\section{Verification of the model}

To begin with, the model we proposed can be supported and explained by established mechanistic models. In 1966, Philip proposed the concept of a complete Soil-Plant-Atmosphere Continuum (SPAC), laying the theoretical foundation for modern farmland water research. Based on this, Meng and Xia (2005) established a dynamic coupling model by calibrating parameters that describes the hydrothermal conditions during crop growth and the law for crop transpiration. Through this coupling model, they hope to reveal the law for moisture and heat transfer of the SPAC. The SPAC is divided into three layers, namely, the atmosphere at a high altitude, the plant canopy which is simplified into one layer at the momentum transfer junction, and the soil layer. To be more specific, the top of the soil layer is set to be the soil surface, and the bottom of the soil layer is set to be at the groundwater level. According to the mathematical expression of total latent and sensible heat consumption of SPAC, the mathematical expression of plant transpiration latent and sensible heat consumption, the mathematical expression of soil evaporation latent and sensible heat consumption, and the model of soil moisture migration and heat transfer, the results obtained from data-driven vector autoregression models can be reasonably explained.

Peer) reviewing PDF | (2018:12:33376:6:0:NEW 1 May 2019) 
380

381

382

383

384

385

386

387

388

389

390

391

392

393

394

395

396

397

398

399

400

401

402

403

404

405

406

407

408

409

410

411

412

413

414

415

416

417

418

419

420

421
To begin with, the lagging effect of impulse response between soil temperature and moisture can be explained as follows. Moisture's lagging effect on temperature can be partly interpreted by the basic heat transfer equation:

$$
C_{\mathrm{v}} \frac{\partial T}{\partial t}=\frac{\partial}{\partial z}\left(K_{\mathrm{h}} \frac{\partial T}{\partial \mathrm{z}}\right)
$$

where $\mathrm{T}$ is soil temperature, $C_{\mathrm{v}}$ is soil volumetric heat capacity, and $K_{\mathrm{h}}$ is soil thermal conductivity. $C_{\mathrm{v}}$ and $K_{\mathrm{h}}$ are close correlated with soil moisture content $\theta$ and can be expressed in the single factor function form of $\theta$. From the equation above, we can deduce that when there is a fluctuation in soil moisture content, the first-order derivative of temperature T's function on time $t$ will change. Thus, although the contemporary value of temperature will not change, it's successive value will change gradually in accordance with the change of the first-order derivative. Finally, at some point after the interference point, the deviation of temperature will reach its maximum, accounting for moisture's lagging effect on temperature. Temperature's lagging effect on moisture is to some extent related to the relationship between water vapor relative saturation and soil temperature.

$$
h_{2}=\exp \left(\frac{M g \psi_{2}}{R\left(T_{2}+273.16\right)}\right)
$$

where $h_{2}$ is the water vapor relative saturation of the air at the soil surface, $\psi_{2}$ represents water potential at the soil surface, $R$ is the universal gas constant, and $T_{2}$ denotes soil surface temperature. Though other possible reasons for the lagging effect may exist, one major process can be deduced from the expression above, where a fluctuation in soil temperature will first cause deviation in water vapor relative saturation, and then change in water vapor relative saturation will cause the corresponding variation in soil moisture through a series of complicated processes. In this way, a time lag exists.

The result that the time lag and intensity of the impulse response change with depth can be explained by several processes, some of which can be expressed as follows.

$$
\begin{gathered}
S_{\mathrm{w}}=\left[(4 m-1) / \operatorname{lr}(t)-(8 m-4) / l r^{2}(t)\right] E_{\mathrm{v}}(t) \\
E_{\mathrm{v}}(t)=\int_{0}^{l r(t)} S_{\mathrm{w}}(z, t) d z
\end{gathered}
$$

Where $S_{\mathrm{w}}$ is the water absorption intensity of roots, $m$ denotes the ratio of water absorption rate of the upper part to that of the lower part of roots, $\operatorname{lr}(t)$ represents root depth, and $E_{\mathrm{v}}$ is crop transpiration rate. Equation (27) describes how $S_{\mathrm{w}}$ is influenced by depth and time. Equation (28) describes the way in which plant transpiration is influenced by $S_{\mathrm{w}}$ at different soil depths (Lei et al., 1988). Given that there exists a close relationship between soil temperature and plant transpiration latent and sensible heat consumption, it can be deduced that soil temperature varies with depth.

In addition to physical explanations, we used data from a different year and partly verified the universality of the model. We collected data on soil temperature and moisture content at the same test site from December $19^{\text {th }}$, 2016 to May $30^{\text {th }}, 2017$ at the depth of $10 \mathrm{~cm}, 30 \mathrm{~cm}$, and $90 \mathrm{~cm}$, during which the same irrigation method, i.e., drip irrigation, has been adopted. Then, we used the same method stated above to build three vector autoregression models. Next, we built impulse response functions and conducted Granger causality tests. The results we obtained are as follows. First, the time lag of soil moisture's impulse response is $30 \mathrm{~h}, 70 \mathrm{~h}$, and longer than $120 \mathrm{~h}$, while the time lag of temperature's impulse response is about $60 \mathrm{~h}$, longer than $120 \mathrm{~h}$, and longer than $120 \mathrm{~h}$ at $10 \mathrm{~cm}, 30 \mathrm{~cm}$, and $90 \mathrm{~cm}$. Second, temperature's response intensity is $0.1989^{\circ} \mathrm{C}, 0.0157^{\circ} \mathrm{C}$ and $0.0031^{\circ} \mathrm{C}$ for $1 \%$ of variation in soil moisture, and moisture's response intensity is $0.0578 \%, 0.0169 \%$ and $0.0057 \%$ for $1^{\circ} \mathrm{C}$ of variation in soil temperature at $10 \mathrm{~cm}, 30 \mathrm{~cm}$ and $90 \mathrm{~cm}$. Third, soil moisture is helpful in terms of predicting soil temperature at the depth of $10 \mathrm{~cm}, 30 \mathrm{~cm}$, and $90 \mathrm{~cm}$. Besides, soil temperature is helpful in terms of predicting soil moisture at the depth of $10 \mathrm{~cm}$ and $30 \mathrm{~cm}$ but has no obvious relationship with soil moisture at $90 \mathrm{~cm}$.

By comparing the results with those of 2017-2018, we can discover that the ratios for the intensity of soil temperature's impulse response to moisture among three depths during both periods approximate 200:16:3. And the ratios for the intensity of moisture's impulse response to temperature during both periods approximate 60:17:6. Moreover, the results of Granger causality tests are the same, indicating certain stability in terms of the physical and biological processes that involve the variation of soil temperature and moisture in the same area. This demonstrates that for the same area the data-driven model we proposed has consistency and the results we obtained are not out

Peer] reviewing PDF | (2018:12:33376:6:0:NEW 1 May 2019) 
422

423

424

425

426

427

428

429

430

431

432

433

434

435

436

437

438

439

440

441

442

443

444

445

446

447

448

449

450

451

452

453

454

455

456

457

458

459

460

461

462

463

464

465

466

467

468

469

470

471

472

of a sudden. Thus, the method of building data-driven vector autoregression models can be used to study the characteristics of soil heat-moisture coupling. Although the numerical results of this model will change with different soil properties in different areas, the method can be applied in the same way. The data and MATLAB code for training and testing the models have been included in the supplementary files for readers to verify our findings.

\section{Conclusions}

We designed a purely data-driven stochastic model for analyzing moisture-heat coupling of a wheat-soil system, which consists of three vector autoregression models built at the depth of $10 \mathrm{~cm}, 30 \mathrm{~cm}$, and $90 \mathrm{~cm}$, impulse response functions, and Granger causality tests. For the empirical test of this method, we use the hourly data on soil moisture and soil temperature at the depth of $10 \mathrm{~cm}, 30 \mathrm{~cm}$, and $90 \mathrm{~cm}$ obtained at Shangqiu Experiment Station. Following conclusions can be drawn from the models.

Firstly, the time lag of soil temperature's influence on soil moisture is for about $25 \mathrm{~h}$ at $10 \mathrm{~cm}, 50 \mathrm{~h}$ at $30 \mathrm{~cm}$, and $120 \mathrm{~h}$ at $90 \mathrm{~cm}$, while the time lag of soil moisture's influence on soil temperature is for about $50 \mathrm{~h}$ at $10 \mathrm{~cm}$ and longer than $120 \mathrm{~h}$ at $30 \mathrm{~cm}$ and $90 \mathrm{~cm}$. Secondly, the intensity of soil temperature's impulse response to shock in soil moisture is $0.2004^{\circ} \mathrm{C}, 0.0163^{\circ} \mathrm{C}$ and $0.0035^{\circ} \mathrm{C}$ for $1 \%$ variation in soil moisture respectively at the depth of $10 \mathrm{~cm}, 30$ $\mathrm{cm}$, and $90 \mathrm{~cm}$. Similarly, the intensity of soil moisture's impulse response is $0.0638 \%, 0.0163 \%$ and $0.0050 \%$ for $1^{\circ} \mathrm{C}$ of variation in soil temperature respectively at the depth of $10 \mathrm{~cm}, 30 \mathrm{~cm}$, and $90 \mathrm{~cm}$. Thirdly, soil moisture is helpful in terms of predicting soil temperature at the depth of $10 \mathrm{~cm}, 30 \mathrm{~cm}$, and $90 \mathrm{~cm}$. While soil temperature helps predict soil moisture at the depth of $10 \mathrm{~cm}$ and $30 \mathrm{~cm}$, it has no obvious correlation with soil moisture at $90 \mathrm{~cm}$.

Although the proposed method for analyzing moisture-heat coupling in a wheat-soil system has some advantages such as data-driven and easy to achieve, there are limitations. One is that the vector autoregression model is based on the linear hypothesis, so other nonlinear data-driven models should be further studied. Also, since the soil of our experiment site is loam, we ought to further explore whether such a method can be applied to other kinds of soil using data from different experiment sites. We are currently working on this.

\section{References}

1. Awad, W., Byrne, P.F., Reid, S.D., Comas, L.H. \& Haley, S.D 2018 Great Plains Winter Wheat Varies for Root Length and Diameter under Drought Stress. Agronomy Journal, 110(1), 226-235, doi: 10.2134/agronj2017.07.0377.

2. Bittelli M., Ventura F., Campbell G. S., Snyder R. L., Gallegati F. \& Pisa P. R. 2008 Coupling of heat, water vapor, and liquid water fluxes to compute evaporation in bare soils. Journal of Hydrology, 362(3-4), 191-205, doi: 10.1016/j.jhydrol.2008.08.014.

3. Bolin D., Wallin J. \& Lindgren F. (in press) Latent Gaussian random field mixture models. Computational Statistics \& Data Analysis, 130, 80-93, doi: 10.1016/j.csda.2018.08.007.

4. Bouri E., Gupta R., Hosseini S. \& Lau C. K. M. 2018 Does global fear predict fear in BRICS stock markets? Evidence from a Bayesian graphical structural VAR model. Emerging Markets Review, 34, 124-142, doi: 10.1016/j.ememar.2017.11.004.

5. Chen L.-J., Ho Y.-H., Hsieh H.-H., Huang S.-T., Lee H.-C. \& Mahajan S. 2018 ADF: an anomaly detection framework for largescale PM2.5 sensing systems. IEEE Internet of Things Journal, 5(2), 559-570, doi: 10.1109/JIOT.2017.2766085.

6. Droumaguet M., Warne A. \& Wozniak T. 2017 Granger Causality and Regime Inference in Markov Switching VAR Models with Bayesian Methods. Journal of Applied Econometrics, 32(4), 802-818, doi: 10.1002/jae.2531.

7. Lei Z. D., Yang S. X., Xie S. C. 1988 Soil Water Dynamics (in Chinese). Tsinghua University Press, 314, doi: 10.13243/j.cnki.slxb.1988.05.001.

8. Liu B. C., Liu W. \& Peng S. W. 2005 Study of heat and moisture transfer in soil with a dry surface layer. International Journal of Heat and Mass Transfer, 48(21-22), 4579-4589, doi: 10.1016/j.ijheatmasstransfer.2005.06.004.

9. Lu N. \& Dong Y. 2015 Closed-Form Equation for Thermal Conductivity of Unsaturated Soils at Room Temperature. Journal of Geotechnical and Geoenvironmental Engineering, 141(6), doi:10.1061/(ASCE)GT.1943-5606.0001295.

10. Mao X. \& Shang P. 2018 Extended AIC model based on high order moments and its application in the financial market. Physical A-statistical Mechanics and Its Applications, 501, 264-275, doi: 10.1016/j.physa.2018.02.159.

11. Meng C.H. \& Xia J. 2005 Research on water and heat transfer in soil-plant-atmosphere system. Journal of Hydrodynamics, 20(3), 307-312, doi: 10.16076/j.cnki.cjhd.2005.03.005.

12. Nassar I. N. \& Horton, R. 1989 Water transport in unsaturated nonisothermal salty soil: II. Theoretical Development. Soil Science Society of America Journal, 53(5), 1330, doi: 10.2136/sssaj1989.03615995005300050005x.

13. Pan Y., Shi G., Liu Y. \& Lee F. 2018 Effect of spatial variability on performance of cement-treated soil slab during deep excavation. Construction and Building Materials, 188, 505-519, doi: 10.1016/j.conbuildmat.2018.08.112.

Peerf reviewing PDF | (2018:12:33376:6:0:NEW 1 May 2019) 
473 474 475 476 477 478 479

480

481

482

483

484

485

486

487

488

489

490

491

492

493

494

14. Philip JR. \& Vries DA. 1957 Moisture movement in porous material sunder temperature gradients. Trans Am Geophy Unionk, 38, 22-231, doi: 10.1029/tr038i002p00222.

15. Perez E. H., Paez M. I. \& Figueroa A. 2013 Effect of moisture and temperature on dissipation of chlorpyrifos and diazinon in andic soils, Cauca, Colombia. Asian Journal of Chemistry, 25(16), 9208-9212, doi: 10.14233/ajchem.2013.15166.

16. Schoukens J., Godfrey K. \& Schoukens M. 2018 Nonparametric data-driven modeling of linear systems estimating the frequency response and impulse response function. IEEE Control Systems Magazines, 38(4), 49-88, doi: 10.1109/MCS.2018.2830080.

17. Striegl \& Loheide 2012 Feasibility of soil moisture estimation using passive distributed temperature sensing. Ground Water, 50(3), 340-347, doi:10.1111/j.1745-6584.2012.00928.x

18. Steele-Dunne S. C., Rutten M. M., Krzeminska D. M., Hausner M., Tyler S. W., Selker J., Bogaard T. A. \& van de Giesen N. C. 2010 Feasibility of soil moisture estimation using passive distributed temperature sensing. Water Resources, 46, W03534, doi:10.1029/2009WR008272.

19. Stokes P. A. \& Purdon P. L. 2018 Regarding interpretation of Granger causality analyses reply. Proceedings of the National Academy of Sciences of the United States of America, 115(29), E6678-E6679, doi: 10.1073/pnas.1807099115.

20. Sun Z., Chen Q., Han X., Bol R., Qu B. \& Meng F. 2018 Allocation of photosynthesized carbon in an intensively farmed winter wheat-soil system as revealed by (CO2)-C-14 pulse labelling. Scientific Reports, 8, doi: 10.1038/s41598-018-21547-y.

21. Whelan A., Kechavarzi C., Coulon F. \& Doerr S. H. 2015 Experimental characterization of the impact of temperature and moisture on the breakdown of soil water repellency in sandy soils and composts. Hydrological Processes, 29(8), 2065-2073, doi: 10.1002/hyp.10305.

22. Yang Y., Shang S. \& Guan H. 2012 Development of a soil-plant-atmosphere continuum model (HDS-SPAC) based on hybrid dual-source approach and its verification in wheat field. Science China Technological Sciences, 55(10), 2671-2685, doi: 10.1007/s11431-012-4974-7. 
Figure 1

Soil temperature (a) and soil humidity (b) at different depths.

Soil temperature (a) and soil humidity (b) at the depth of $10 \mathrm{~cm}-100 \mathrm{~cm}$ obtained at the Shangqiu test site, China.
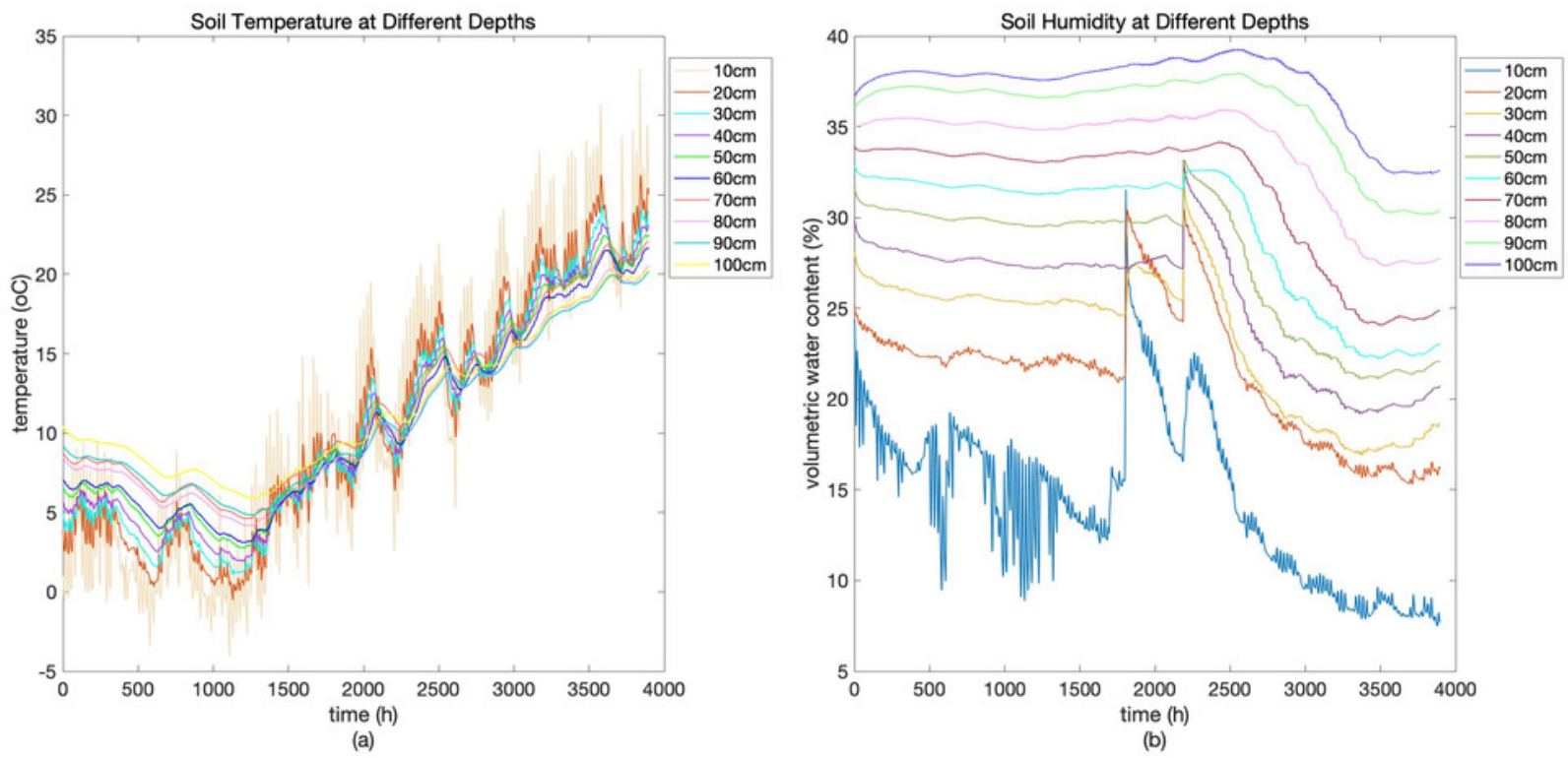
Figure 2

Deseasonalized soil temperature (a) and moisture (b) at the depth of $10 \mathrm{~cm}, 30 \mathrm{~cm}$, and $90 \mathrm{~cm}$.

Soil temperature (a) and moisture (b) after deseasonalization at the depth of $10 \mathrm{~cm}, 30 \mathrm{~cm}$, and $90 \mathrm{~cm}$.

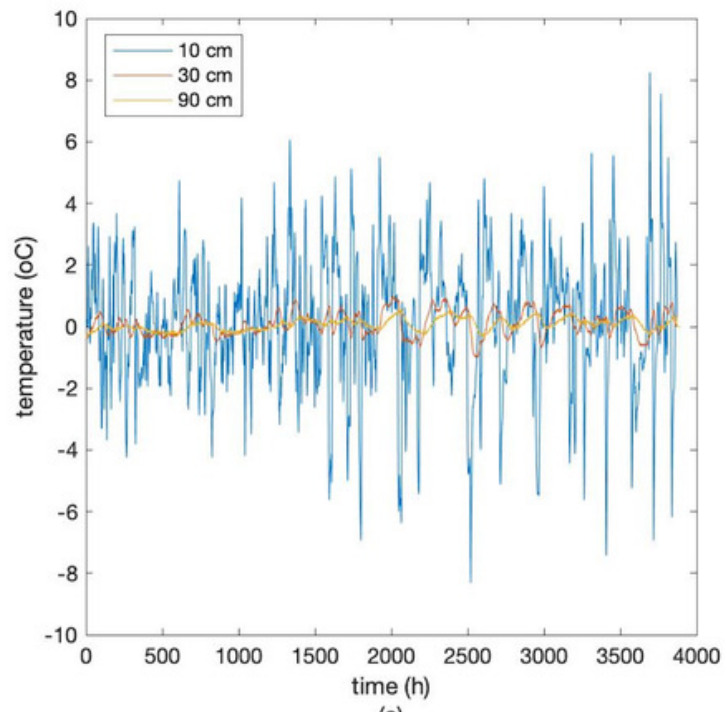

(a)

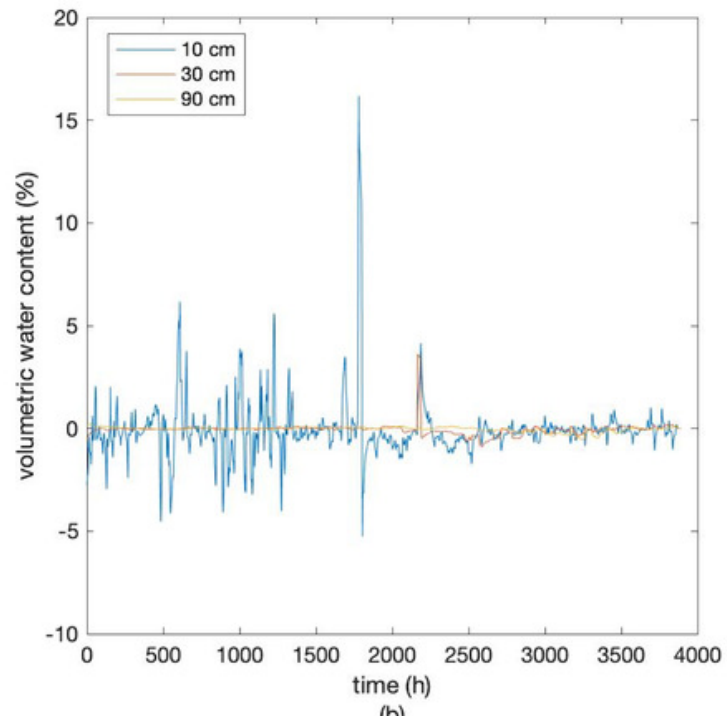

(b) 
Figure 3

Inverse roots of AR characteristic polynomial at $10 \mathrm{~cm}$ (a), $30 \mathrm{~cm}$ (b) and $90 \mathrm{~cm}$ (c).

In this complex plane, the horizontal axis is the real axis, and the vertical axis is the imaginary axis. Inverse roots of AR characteristic polynomial at $10 \mathrm{~cm}$ (a), $30 \mathrm{~cm}$ (b) and 90 $\mathrm{cm}$ (c) show that all three models are stationary.

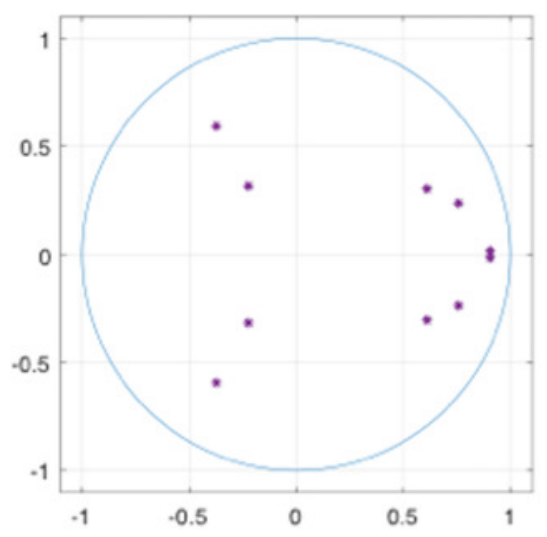

(a)

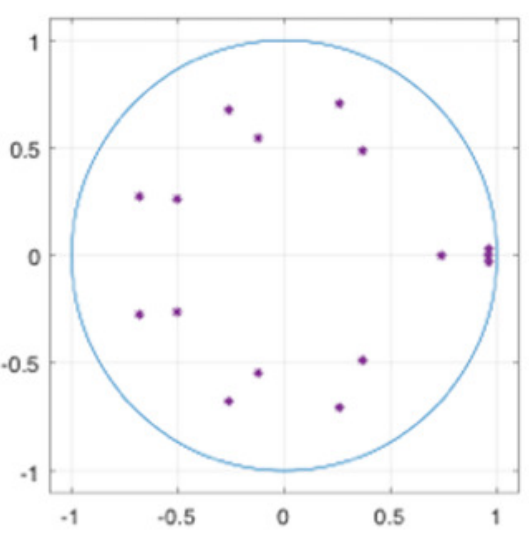

(b)

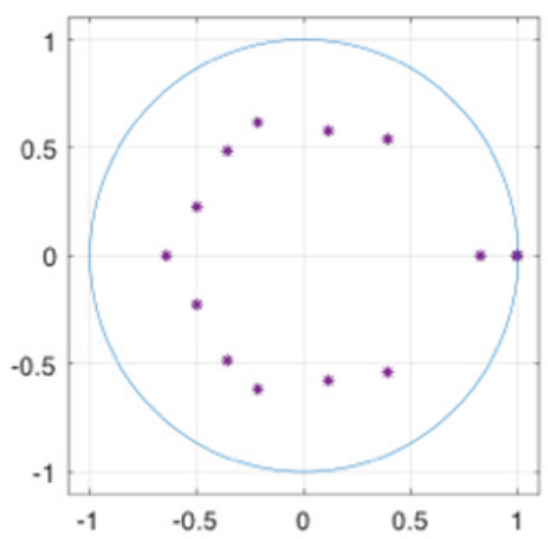

(c) 


\section{Figure 4}

Impulse response results.

Impulse response of MCSD10 to shock in STSD10 (a), impulse response of STSD10 to shock in MCSD10 (b), impulse response of MCSD30 to shock in STSD30 (c), impulse response of STSD30 to shock in MCSD30 (d), impulse response of MCSD90 to shock in STSD90 (e), impulse response of STSD90 to shock in MCSD90 (f). The solid line of blue fluorescence represents the impulse response and the red dashed line represents the confidence interval of the impulse response with a confidence level of 0.90 .

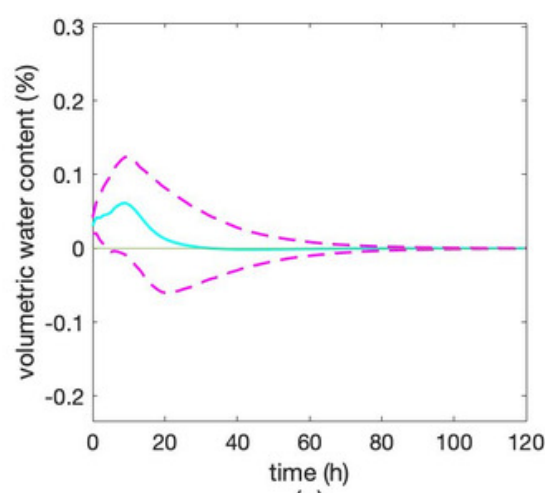

(a)

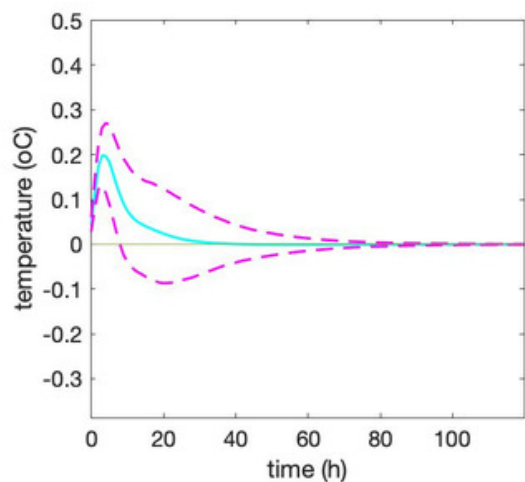

(b)

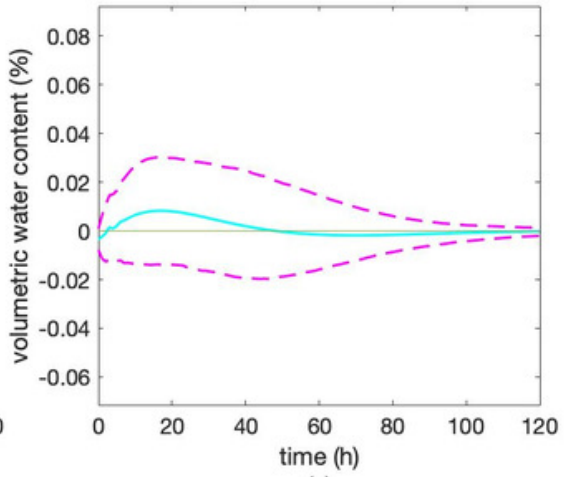

(c)

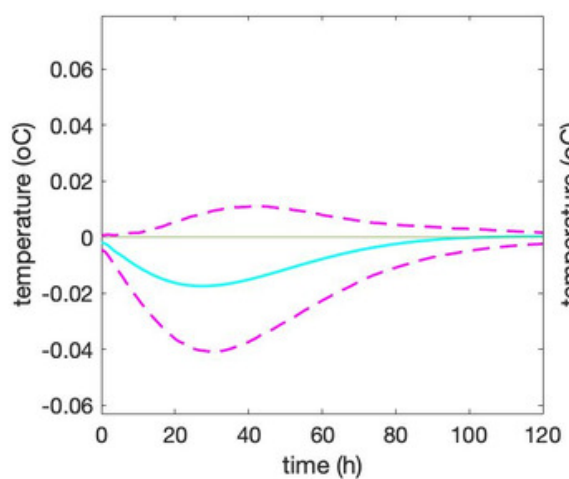

(d)

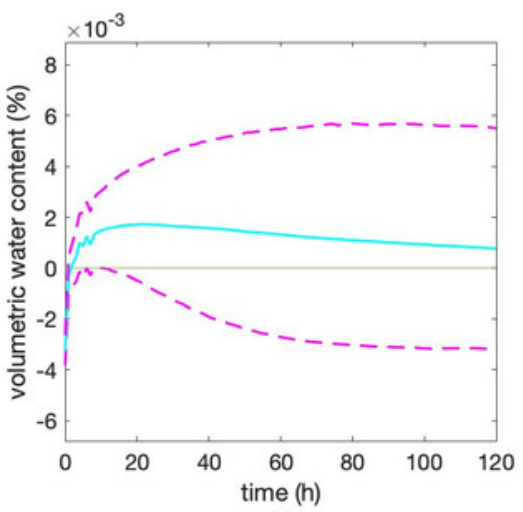

(e)

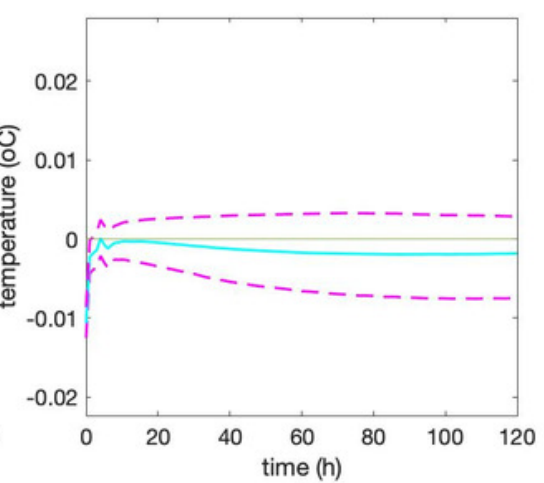

(f) 


\section{Table $\mathbf{1}$ (on next page)}

Unit root test results of the deseasonalizedsoil moisture and temperature time series.

${ }^{1} T$ stat.is the t-statistic for performing ADF test. ${ }^{2}$ Modelindicates the type of hypothesis selected and the lag period which is added to make the residual become white noise. ${ }^{3} P$ Valuerepresents the corresponding $\mathrm{p}$ value. ${ }^{4} \mathrm{C} . \mathrm{V}$. indicates critical value. ${ }^{5} *$ indicates a significant level of $10 \%, * *$ indicates a significant level of $5 \%$, and $* * *$ indicates a significant level of $1 \% .{ }^{6}$ Stationary indicates that the time series is stable. 
1 Table 1. Unit root test results of the deseasonalized soil moisture and temperature time series.

\begin{tabular}{cccccccc}
\hline Variable & T stat. $^{1}$ & Model $^{2}$ & P-Value $^{3}$ & $1 \% C . V .{ }^{4}$ & $5 \% C . V$. & $10 \% C . V$. & Conclusion \\
\hline MCSD10 & -11.273 & $\mathrm{AR}(8)$ & $0.001 * * * 5$ & -2.568 & -1.942 & -1.617 & Stationary $^{6}$ \\
STSD10 & -11.689 & $\mathrm{AR}(5)$ & $0.001 * * *$ & -2.568 & -1.942 & -1.617 & Stationary \\
MCSD30 & -8.590 & $\mathrm{AR}(3)$ & $0.001 * * *$ & -2.568 & -1.942 & -1.617 & Stationary \\
STSD30 & -7.423 & $\mathrm{AR}(8)$ & $0.001 * * *$ & -2.568 & -1.942 & -1.617 & Stationary \\
MCSD90 & -3.927 & $\mathrm{AR}(8)$ & $0.001 * * *$ & -2.568 & -1.942 & -1.617 & Stationary \\
STSD90 & -2.055 & $\mathrm{AR}(8)$ & $0.039 * *$ & -2.568 & -1.942 & -1.617 & Stationary \\
\hline
\end{tabular}

$2{ }^{1} T$ stat. is the t-statistic for performing ADF test. ${ }^{2}$ Model indicates the type of hypothesis selected and the lag period which is 3 added to make the residual become white noise. ${ }^{3} P$-Value represents the corresponding $p$ value. ${ }^{4} \mathrm{C} . \mathrm{V}$. indicates critical value. ${ }^{5 *}$ 4 indicates a significant level of $10 \%, * *$ indicates a significant level of $5 \%$, and *** indicates a significant level of $1 \% .{ }^{6}$ Stationary 5 indicates that the time series is stable. 


\section{Table 2 (on next page)}

Calculated $\operatorname{In}(\mathrm{L}), \mathrm{AIC}$ and $\mathrm{BIC}$ for vector auto-regression models of different lags at the depth of $10 \mathrm{~cm}, 30 \mathrm{~cm}$, and $90 \mathrm{~cm}$.

The first row of the table denotes the possible lag orders of the model. The table is used to choose the optimal lag order for each model by comparing the value $\operatorname{In}(\mathrm{L})$, AIC and BIC. 
1 Table 2. Calculated $\operatorname{In}(\mathrm{L}), \mathrm{AIC}$ and BIC for vector auto-regression models of different lags at the depth of $10 \mathrm{~cm}, 30 \mathrm{~cm}$, 2 and $90 \mathrm{~cm}$.

\begin{tabular}{|c|c|c|c|c|c|c|c|c|c|}
\hline \multirow{2}{*}{ Lag } & \multicolumn{3}{|c|}{$10 \mathrm{~cm}$} & \multicolumn{3}{|c|}{$30 \mathrm{~cm}$} & \multicolumn{3}{|c|}{$90 \mathrm{~cm}$} \\
\hline & $\ln (\hat{L})$ & AIC & $\mathrm{BIC}$ & $\ln (\hat{L})$ & AIC & $\mathrm{BIC}$ & $\ln (\hat{L})$ & AIC & $\mathrm{BIC}$ \\
\hline 1 & -2298.5 & 4609.1 & 4646.6 & 11500.7 & -22989.4 & -22951.8 & 19089.2 & -38166.3 & -38128.8 \\
\hline 2 & 242.7 & -465.5 & -402.9 & 11758.8 & -23497.7 & -23435.1 & 19625.2 & -39230.3 & -39167.7 \\
\hline 3 & 277.9 & -527.8 & -440.1 & 11762.2 & -23496.5 & -23408.8 & 19814.5 & -39600.9 & -39513.3 \\
\hline 4 & 327.8 & -619.6 & -507.0 & 11826.4 & -23616.9 & -23504.2 & 19927.4 & -39818.8 & -39706.1 \\
\hline 5 & 478.2 & -912.4 & -774.7 & 11942.4 & -23840.7 & -23703.0 & 20013.4 & -39982.9 & -39845.1 \\
\hline 6 & 493.0 & -934.1 & -771.3 & 12050.5 & -24048.9 & -23886.2 & 20035.8 & -40019.7 & -39856.9 \\
\hline 7 & 493.2 & -926.4 & -738.6 & 12102.0 & -24144.1 & -23956.3 & 20054.4 & -40048.7 & -39860.9 \\
\hline 8 & 508.4 & -948.8 & -736.0 & 12143.2 & -24218.3 & -24005.5 & 20068.5 & -40069.0 & -39856.2 \\
\hline
\end{tabular}

3 


\section{Table 3(on next page)}

Impulse response results of MCSD10, STSD10, MCSD30, STSD30, MCSD90 and STSD90.

The first column of the table denotes retrospective periods with its unit being hour. And the next six columns display the results of response of MCSD to one unit of positive shock in STSD (\%) and response of MCSD to one unit of positive shock in STSD (\%). 
1 Table 3. Impulse response results of MCSD10, STSD10, MCSD30, STSD30, MCSD90 and STSD90.

\begin{tabular}{|c|c|c|c|c|c|c|}
\hline $\begin{array}{l}\mathrm{RP}^{1} \\
\text { (h) }\end{array}$ & $\begin{array}{l}\text { Response of } \\
\text { MCSD10 to one } \\
\text { unit of positive } \\
\text { shock in } \\
\text { STSD10(\%) }\end{array}$ & $\begin{array}{l}\text { Response of } \\
\text { STSD } 10 \text { to one } \\
\text { unit of positive } \\
\text { shock in } \\
M C S D 1 O\left({ }^{\circ} \mathrm{C}\right)\end{array}$ & $\begin{array}{l}\text { Response of } \\
M C S D 30 \text { to one } \\
\text { unit of positive } \\
\text { shock in } \\
\text { STSD30(\%) }\end{array}$ & $\begin{array}{l}\text { Response of } \\
\text { STSD } 30 \text { to one } \\
\text { unit of positive } \\
\text { shock in } \\
M C S D 3 O\left({ }^{\circ} \mathrm{C}\right)\end{array}$ & $\begin{array}{c}\text { Response of } \\
\text { MCSD90 to one } \\
\text { unit of positive } \\
\text { shock in } \\
\text { STSD90(\%) }\end{array}$ & $\begin{array}{l}\text { Response of } \\
\text { STSD90 to one } \\
\text { unit of positive } \\
\text { shock in } \\
M C S D 90\left({ }^{\circ} \mathrm{C}\right)\end{array}$ \\
\hline 0 & 0.0312 & 0.0453 & -0.0077 & -0.0045 & -0.0033 & -0.0107 \\
\hline 1 & 0.0426 & 0.1112 & -0.0046 & -0.0029 & -0.0003 & -0.0024 \\
\hline 2 & 0.0410 & 0.1695 & -0.0051 & -0.0051 & 0.0002 & -0.0018 \\
\hline 3 & 0.0434 & 0.1942 & -0.0033 & -0.0044 & 0.0004 & -0.0015 \\
\hline 4 & 0.0449 & 0.2004 & -0.0033 & -0.0048 & 0.0010 & -0.0000 \\
\hline 5 & 0.0470 & 0.1876 & -0.0019 & -0.0064 & 0.0009 & -0.0008 \\
\hline 6 & 0.0530 & 0.1581 & -0.0011 & -0.0063 & 0.0013 & -0.0014 \\
\hline 7 & 0.0584 & 0.1268 & 0.0011 & -0.0070 & 0.0009 & -0.0009 \\
\hline 8 & 0.0620 & 0.0973 & 0.0019 & -0.0073 & 0.0013 & -0.0006 \\
\hline 9 & 0.0638 & 0.0718 & 0.0025 & -0.0081 & 0.0014 & -0.0006 \\
\hline 10 & 0.0626 & 0.0543 & 0.0036 & -0.0085 & 0.0015 & -0.0005 \\
\hline 11 & 0.0586 & 0.0433 & 0.0045 & -0.0091 & 0.0015 & -0.0004 \\
\hline 12 & 0.0531 & 0.0374 & 0.0054 & -0.0096 & 0.0016 & -0.0005 \\
\hline
\end{tabular}

$2 \quad{ }^{1} \mathrm{RP}$ represents retrospective periods, its unit is hour. 


\section{Table 4 (on next page)}

Granger causality test determining whether STSD10 Granger causes MCSD10.

The table displays the results of Granger causality test of the depth of $10 \mathrm{~cm}$. By comparing the value of F-Statistics and critical values at the significance level of $0.01,0.05$ and 0.10 , we can deduce the Granger causal relationship between soil moisture and temperature. 
1 Table 4. Granger causality test determining whether STSD10 Granger causes MCSD10.

\begin{tabular}{cccc}
\hline Significance & F-Statistic & Critical Value & Conclusion \\
\hline 0.01 & 0.5694 & 6.6415 & NO \\
0.05 & 0.5694 & 3.8439 & NO \\
0.10 & 0.5694 & 2.7068 & NO \\
\hline
\end{tabular}

2 


\section{Table 5 (on next page)}

Granger causality test determining whether MCSD10 Granger causes STSD10.

The table displays the results of Granger causality test of the depth of $10 \mathrm{~cm}$. By comparing the value of F-Statistics and critical values at the significance level of $0.01,0.05$ and 0.10 , we can deduce the Granger causal relationship between soil moisture and temperature. 
1 Table 5. Granger causality test determining whether MCSD10 Granger causes STSD10.

\begin{tabular}{cccc}
\hline Significance & F-Statistic & Critical Value & Conclusion \\
\hline 0.01 & 18.3573 & 3.3240 & YES \\
0.05 & 18.3573 & 2.3742 & YES \\
0.10 & 18.3573 & 1.9463 & YES \\
\hline
\end{tabular}

2 


\section{Table 6 (on next page)}

Granger causality test determining whether STSD30 Granger causes MCSD30.

The table displays the results of Granger causality test of the depth of $30 \mathrm{~cm}$. By comparing the value of F-Statistics and critical values at the significance level of $0.01,0.05$ and 0.10 , we can deduce the Granger causal relationship between soil moisture and temperature. 
1 Table 6. Granger causality test determining whether STSD30 Granger causes MCSD30.

\begin{tabular}{cccc}
\hline Significance & F-Statistic & Critical Value & Conclusion \\
\hline 0.01 & 12.7695 & 4.6107 & YES \\
0.05 & 12.7695 & 2.9981 & YES \\
0.10 & 12.7695 & 2.3040 & YES \\
\hline
\end{tabular}

2 


\section{Table 7 (on next page)}

Granger causality test determining whether MCSD30 Granger causes STSD30.

The table displays the results of Granger causality test of the depth of $30 \mathrm{~cm}$. By comparing the value of F-Statistics and critical values at the significance level of $0.01,0.05$ and 0.10 , we can deduce the Granger causal relationship between soil moisture and temperature. 
1 Table 7. Granger causality test determining whether MCSD30 Granger causes STSD30.

\begin{tabular}{cccc}
\hline Significance & F-Statistic & Critical Value & Conclusion \\
\hline 0.01 & 4.2014 & 6.6415 & NO \\
0.05 & 4.2014 & 3.8439 & YES \\
0.10 & 4.2014 & 2.7068 & YES \\
\hline
\end{tabular}

2 


\section{Table 8(on next page)}

Granger causality test determining whether STSD90 Granger causes MCSD90.

The table displays the results of Granger causality test of the depth of $90 \mathrm{~cm}$. By comparing the value of F-Statistics and critical values at the significance level of $0.01,0.05$ and 0.10 , we can deduce the Granger causal relationship between soil moisture and temperature. 
1 Table 8. Granger causality test determining whether STSD90 Granger causes MCSD90.

\begin{tabular}{cccc}
\hline Significance & F-Statistic & Critical Value & Conclusion \\
\hline 0.01 & 40.9051 & 2.6439 & YES \\
0.05 & 40.9051 & 2.0120 & YES \\
0.10 & 40.9051 & 1.7183 & YES \\
\hline
\end{tabular}

2 


\section{Table 9 (on next page)}

Granger causality test determining whether MCSD90 Granger causes STSD90.

The table displays the results of Granger causality test of the depth of $90 \mathrm{~cm}$. By comparing the value of F-Statistics and critical values at the significance level of $0.01,0.05$ and 0.10 , we can deduce the Granger causal relationship between soil moisture and temperature. 
1 Table 9. Granger causality test determining whether MCSD90 Granger causes STSD90.

\begin{tabular}{cccc}
\hline Significance & F-Statistic & Critical Value & Conclusion \\
\hline 0.01 & 10.5937 & 3.0220 & YES \\
0.05 & 10.5937 & 2.2164 & YES \\
0.10 & 10.5937 & 1.8488 & YES \\
\hline
\end{tabular}

2 